\title{
A TRANSFORMAÇÃO NA HISTÓRIA DA ARQUITETURA ESCOLAR
}

Korina Costa, Liza da Fonseca Jeronymo

Universidade do Oeste Paulista - UNOESTE, Faculdade de Engenharias e Arquitetura e Urbanismo, Presidente Prudente, SP. E-mail: korina.ara@gmail.com

\section{RESUMO}

O presente artigo aborda a história da arquitetura escolar desde seus primórdios no mundo e no Brasil. Através da análise de alguns estudiosos sobre o assunto, mostra-se necessário a criação de um ambiente adequado para o ensino escolar nos dias atuais, pois o bom projeto arquitetônico influencia diretamente os melhores desempenhos no aprendizado dos alunos e no exercício da profissão dos demais profissionais. De tal modo, como toda boa arquitetura, é preciso levar em consideração as questões de conforto acústico, luminotécnico e térmico, além de que os ambientes devem ser organizados de maneira a gerar segurança e conforto aos usuários.

Palavras-chave: arquitetura escolar; Brasil; Grupo Escolar; educação; FDE.

\section{THE TRANSFORMATION IN ARCHITECTURE SCHOOL HISTORY}

\begin{abstract}
This article discusses about the history of school architecture from its beginnings in the world and in Brazil. Through the analysis of some scholars on the subject, creating a suitable environment for school education is shown necessary today, because the good architectural design directly influences the best performance on student learning and the professional qualifications of other professionals. So, like all good architecture design, it must to take into account the acoustic comfort issues, luminal and heat, and the environments should be organized in order to create security and comfort to the users.

Keywords: school architecture; Brazil; Schoolar Group; education; FDE.
\end{abstract}




\section{INTRODUÇÃO}

Desde os primórdios da humanidade o ato de ensinar as novas gerações existe e se desenvolve até os dias atuais, cada povo e cada cultura a seu modo. Ainda existe, por exemplo, crianças que são educadas dentro dos lares pelos próprios pais; todavia, o mais comum nos dias de hoje, é o prédio escolar como ambiente de ensino, enquanto os professores são os educadores (MELATTI, 2004).

A partir de tal conhecimento, Kowaltowski (2011) e outros inúmeros estudiosos definem que uma boa ou má arquitetura influência diretamente no aprendizado e desempenho do aluno. Cabe, portanto, ao arquiteto comunicar-se diretamente neste processo de aprendizagem e ensino fazendo um projeto bem elaborado, uso adequado de materiais construtivos, integração com a natureza, estudo das cores e outras técnicas construtivas (MELATTI, 2004).

Por meio de releitura da educação na história da humanidade, nota-se o quanto ela sofreu uma gradativa decadência ao longo das últimas décadas, especialmente em território nacional. A partir destas análises, tem-se por objetivo discutir o espaço do ambiente escolar, de maneira a organizá-lo seguindo os padrões da boa arquitetura, respeitando seu entorno e fazendo uso de tecnologias construtivas e projetuais para maior conforto dos usuários. Ou seja, tem por meta principal integrar o projeto arquitetônico ao método de ensino a ser utilizado (Sistema Preventivo) e organizar o ambiente escolar para melhor desempenho intelectual e físico dos alunos e professores.

\section{METODOLOGIA}

O presente artigo baseia-se em uma metodologia qualitativa, que se fundamenta a partir de leituras sobre os sistemas de ensino utilizado nas escolas nos dias de hoje; fichamentos e estudos sobre a história da educação em um panorama mundial e dentro do Brasil e, como sua arquitetura vem se desenvolvendo; e também se baseará em análises de antecedentes, assim como a aplicação de tais estudos na análise de uma edificação escolar prudentina, a qual foi o centro da pesquisa, cujo levantamento de dados ocorreu através de visitas in loco, levantamentos fotográficos, documentais e métricos, cujas ponderações seguem as recomendações da Fundação para Desenvolvimento da Educação (FDE).

Tais estudos seguem os direcionamentos dados por Teixeira (2000), que define a pesquisa qualitativa como aquela que perpassa pela revisão bibliográfica e teórica, de resgate do pensamento conceitual, direciona os procedimentos para coletas de dados e estudos, estimando que tais passos dependem da interpretação particular ao pesquisador, que culminará na análise do objeto em estudo, aliando os resultados dor levantamentos teóricos aos experimentais e também das análises da edificação em estudo.

\section{DISCUSSÃO SOBRE A ARQUITETURA ESCOLAR NO MUNDO}

De acordo com os estudos relacionados à história da arquitetura escolar, é possível destacar os quatro períodos mais significantes desta tipologia construtiva. Primeiramente, durante a Antiguidade a arquitetura escolar era inexistente já que o ensino acontecia dentro dos próprios lares pelos pais ou pelos escribas; entretanto, vale ressaltar que este ensino acontecia num pátio central para que o "aluno" fosse melhor vigiado (MELATTI, 2004).

A partir da Antiguidade até o século XV as construções escolares passam a ser caracterizadas por possuírem sala de aula única e pela moradia do professor estar vinculada a esta sala; o sótão era ocupado por alunos carentes e seminaristas. Esta tipologia continuou a ser referência para as escolas do meio rural. Já durante os séculos XVI e XVII surgem as escolas jesuítas que fazem mudanças no processo de educação como separar salas de aula por idade e, suas edificações escolares passam a ter suas salas de aula ordenadas ao longo de um corredor 
central ou lateral e os dormitórios dos alunos carentes continuam se localizando no sótão (KOWALTOWSKI, 2011).

Durante a Primeira Guerra Mundial, no século XX, inúmeras mudanças começaram a acontecer no sistema educacional e consequentemente, no ambiente escolar: os ideais modernistas, que podem ser definidos em uma palavra, integração. Brubaken (apud KOWALTOWSK, 2011, p. 76) descreve estas construções retilíneas e simplificadas (modernistas), como construções de aparência industrializada, que recordam "caixas de sapato".

No Brasil, entretanto, pouco se tem registros da arquitetura escolar nos primeiros séculos de sua descoberta. Sabe-se que foi nesta época que a construção escolar chegou juntamente com os jesuítas da Companhia de Jesus, que tinham por objetivo principal a catequização dos índios e, com o passar das décadas, a educação dos filhos dos colonos. Para tanto, criou-se o Pátio do Colégio em São Paulo, São Vicente e Bahia pelo padre Manuel da Nóbrega e José de Anchieta (NISKIER, 2001).

Durante a Primeira República (final do século XIX até 1920) os prédios escolares buscam características da arquitetura neoclássica através da imponência, simetria, pé-direito elevado e andar térreo acima do nível da rua. A organização interna das salas se aula se dá em função da disciplina, cada aluno ocupa seu lugar e o professor fica a frente de todos, em posição de autoridade e supervisão; ou seja, relacionam-se o poder e o saber (KOWALTOWSKI, 2011). Neste período o Estado criou medidas padronizadas e racionais por meio dos Grupos Escolares (Lei no 169, de 07 de agosto de 1893, e Decreto 248, de 26 de setembro de 1894) (MARIANO, 2013).

Após as manifestações da Semana de Arte Moderna de 1922 e outros movimentos como a Revolução de 1930, os prédios escolares passaram a ser construídos com características arquitetônicas modernas, sem referência a estilos históricos, mais racional e funcionalista: menos compactos, liberdade na implantação, uso de pilotis para obtenção de térreo livre para as atividades de lazer (Buffa; Pinto, 2002). Neste contexto, outros novos ideais surgiram e começaram a ser aplicados ao projeto arquitetônico, como as salas de aula amplas, claras e bemventiladas, pintadas entre o creme e o verde-claro, além de outras dependências que deveriam apresentar, como um auditório, sala de educação física, biblioteca, instalações para assistência médica e dentária, e outros (FDE).

Juntamente com estas mudanças no repertório da arquitetura escolar brasileira, Anísio Teixeira (1900-1971), Secretário da Educação da Bahia a partir de 1947, deixou-se influenciar pelas escolas comunitárias americanas e apresentou um sistema educacional complementar ao ensino que acontecia dentro das salas de aula. Assim, projetou a escola-parque Carneiro Ribeiro (FIGURA 5) idealizada na cidade de Salvador; a qual pode ser caracterizada como uma arquitetura progressista, aproveitando seus terrenos a fim de baratear o atendimento às demandas sociais (ARANHA, 2006).

Como consequências da política econômica que se seguiu no período de 1960 a 1990, foram adotadas medidas projetuais para reduzir os custos e os prazos de construção (XAVIER; LEMOS; CORONA, 1983 apud KOWALTOLSKI, 2011, p. 91). Dessa maneira, a racionalização escolar pôde ser observada através dos elementos pré-fabricados, como estrutura de concreto independente, fechamento do tipo alvenaria de tijolos, telhas de fibrocimento ou lajes préfabricadas impermeabilizadas. Algumas outras especificações passaram a ser consideradas importantes no processo da implantação das escolas, entre elas podemos citar os acessos e fluxos do entorno e do interior da escola quando relacionadas com a infraestrutura urbana e as vias de trânsito.

Já nos últimos quarenta anos, apensar da arquitetura escolar ser padronizada na maioria dos Estados brasileiros, as fachadas feitas por escritórios terceirizados, conferiram certa originalidade nas fachadas, baseando-se na comunidade em que estava sendo inserida. 0 programa de necessidades das nossas atuais escolas passou a incluir quadra de esportes coberta e 
sala de informática. Dessa forma, as quadras cobertas passam a incorporar à comunidade imediata das escolas, pois são utilizadas aos finais de semana para atividades de lazer e culturais (KOWALTOWSKI, 2011).

Nos dias de hoje, no século XXI, tanto no exterior quanto no Brasil, busca-se as edificações de alto desempenho. Nelas, o arquiteto esforça-se em reduzir o custo de operação e o impacto ambiental, faz uso eficiente da água, ou seja, a sustentabilidade nos mínimos aspectos; e a melhoria da qualidade de vida dos usuários se dá através de uma arquitetura eficiente e que usa da natureza para criar ambientes confortáveis e agradáveis a todos, "(térmica e acusticamente, e nos aspectos visuais)" (KOWALTOWSK, 2011, p. 78).

\section{RESULTADOS OBTIDOS ATRAVÉS DE ANÁLISE DE ESTUDO DE CASO}

Como maneira para melhor compreensão da evolução da arquitetura escolar através das décadas, foi realizado um estudo de caso no Colégio Cooperativo, escola particular de Presidente Prudente que teve seu início através de reuniões de grupos de pais descontentes com a Educação Pública e impossibilitados em arcar com as despesas de uma escola privada de alto padrão. Criaram então, no município, o colégio por meio de Cooperativas de Ensino (COOPERATIVO, 201?).

Em 1993 o Colégio passou a funcionar na região Noroeste do município de Presidente Prudente, no Jardim Carandá. Sua localização conta ao redor com bairros majoritariamente residenciais e alguns poucos comércios locais; fato que evidencia ser uma área adequada para a implantação de uma escola, pois corresponde a uma região relativamente tranquila. Desde sua fundação, a escola passou por inúmeras adaptações para atender seus alunos e funcionários de maneira mais adequada e de acordo com as normas estabelecidas pelo FDE (Fundação para o Desenvolvimento da Educação) (COOPERATIVO, 201?).

O projeto arquitetônico desenvolve-se em toda a extensão do terreno em que está implantado e conta com a construção de quatro blocos distintos. O primeiro bloco é constituído de apenas um pavimento e abriga as atividades administrativas, sala de informática e espaço para cuidados das crianças do maternal. Enquanto isso, o segundo bloco é composto por dois pavimentos; sendo que no térreo, encontram-se: salas de aula do Ensino Infantil ao Ensino Fundamental I; sanitários distintos para estes dois níveis de ensino e; sala para guarda de material de limpeza e almoxarifado, adjacentes às escadas de acesso ao pavimento superior. Ainda no segundo bloco, o pavimento de cima é composto apenas pelas salas de aula dos Ensinos Fundamental II e Médio; laboratório de química e sanitários. O terceiro bloco é onde acontecem os serviços do refeitório destinado para uso exclusivo das crianças do maternal; acima foi construída a biblioteca do Colégio, que tem acesso por uma única escada. Ao lado dele, está locado o último bloco que abriga a cantina e tem acesso direto ao pátio coberto.

O pátio coberto, posicionado ao centro do terreno, é o ponto estratégico de encontro dos alunos durante os horários de intervalo; assim como a quadra poliesportiva que fica ao fundo do terreno. 


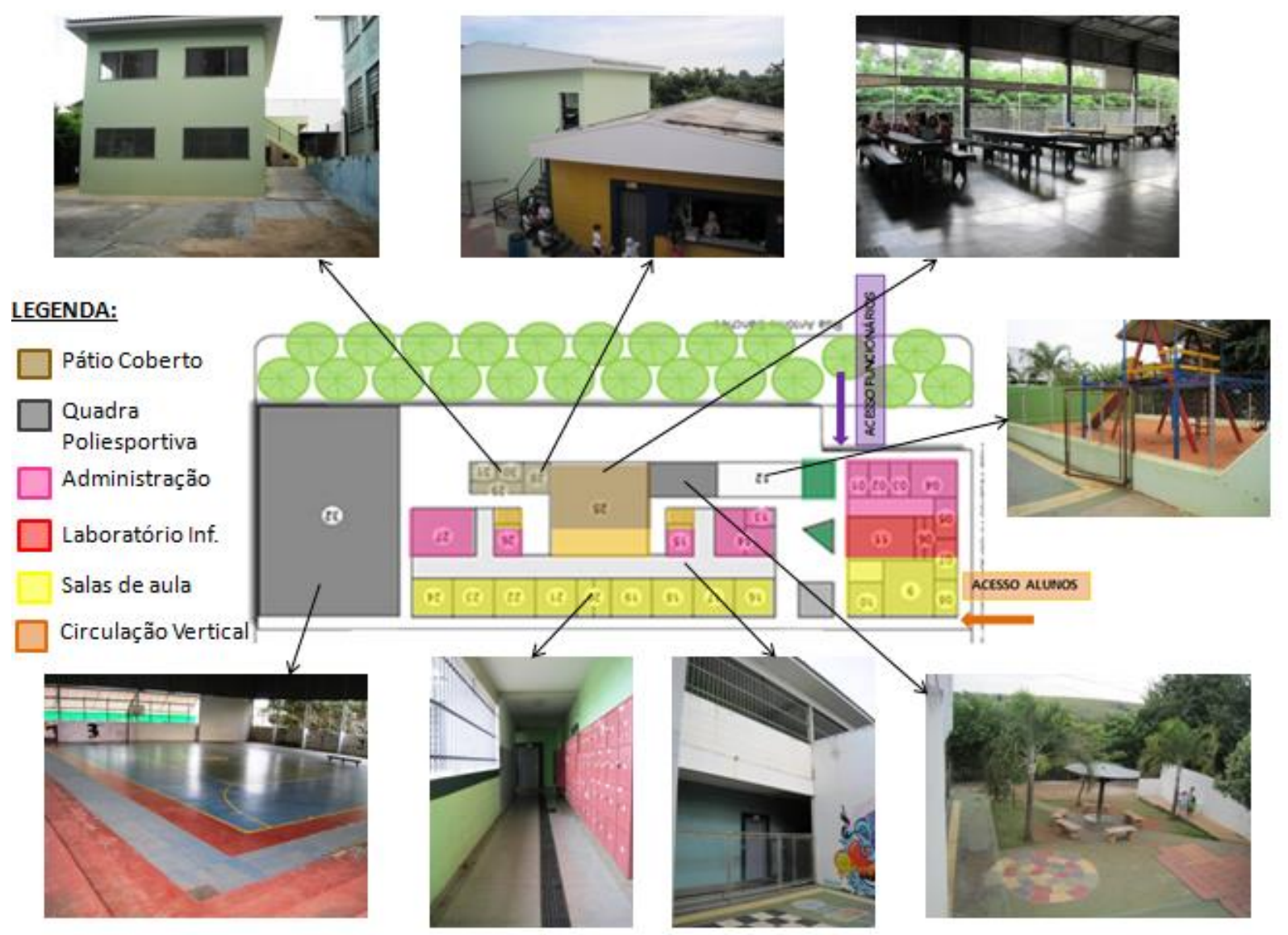

Figura 01. Implantação, setorização e detalhamentos Fonte: Cooperativo (201?). Modificado: autor (2016).

Sobre os acessos, existem entradas distintas para os alunos e para os funcionários. 0 acesso dos alunos se dá na fachada leste da edificação, por meio de rampa que percorre todo o primeiro bloco; enquanto a entrada dos funcionários se localiza na fachada norte e tem acesso direto a área administrativa. Ambos os acessos são cobertos com telha de alumínio, a qual gera intenso calor e desconforto para os alunos durante os longos verões da cidade. Ao lado da entrada de funcionários há um portão de acesso para carros e até mesmo caminhões, quando acontecem festas escolares.

A medida estrutural adotada nesta construção faz uso de alvenaria e de um sistema de concreto armado pré-fabricado industrializado; e o piso das áreas internas é em granilite. Quanto à ventilação e iluminação natural das salas de aula, não são eficazes pelo fato das janelas serem basculantes e utilizarem vidro muito espesso, que não permite a passagem adequada da luz solar. Em algumas salas de aula, já existe até mesmo a presença de ar condicionado.

A circulação entre os pavimentos é feita por escadas de dois lances que estão presentes em ambas as extremidades do segundo bloco. Em caso de alunos com necessidades especiais, faz-se uso da rampa localizada no centro do pátio coberto. 

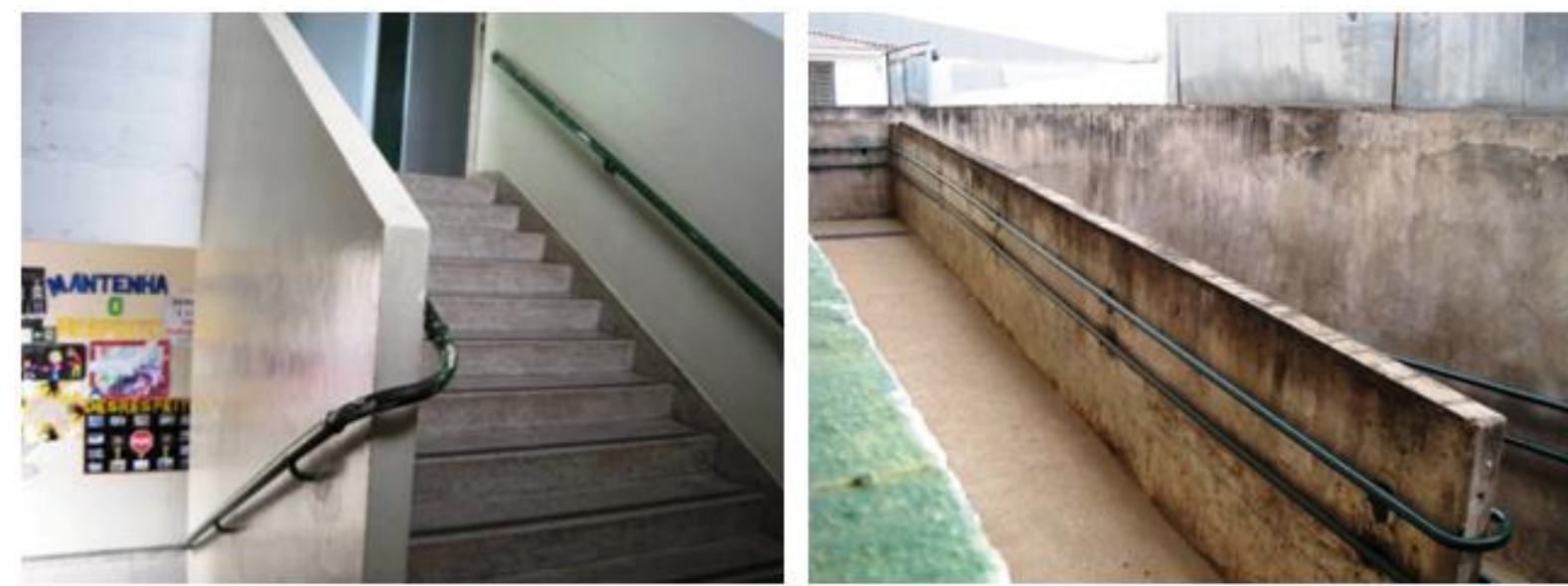

Figura 02. Circulação vertical

Fonte: Autor (2014).

Ainda tratando sobre a acessibilidade desta escola, destaca-se sua constante adaptação ao exigido pelas Normas, inclusive através da utilização de piso podo tátil. No interior das salas de aula e do refeitório, os mobiliários destinados às crianças da Educação Infantil são totalmente adequados a sua estatura e habilidades.

\section{CONCLUSÃO}

Com o presente artigo, procurou-se aprofundar os conhecimentos sobre a arquitetura escolar através de estudos da trajetória desta tipologia construtiva ao longo dos séculos em breve panorama mundial e nacional.

A análise de sua evolução permite a compreensão da influência do espaço escolar no desempenho dos alunos e dos demais profissionais que atuam neste prédio, pois está diretamente relacionada ao conforto ambiental, como acústica, temperatura do ambiente, acessibilidade, qualidade do edifício e outros.

Através do estudo de caso, nas experiências pessoais e, das pesquisas levantadas, entretanto, nota-se não apenas em Presidente Prudente - SP, mas em grande número das escolas brasileiras, que estas não foram devidamente projetadas para o uso que abrigam. A maior parte são prédios que vem se adaptando ao longo dos anos para melhor receber os alunos e os funcionários, de maneira que somente se enquadram nas normas e padrões exigidos pela FDE e pela NBR 9050, não cumprindo as necessidades básicas do conforto ambiental para garantia de melhor desempenho de seus usuários.

\section{REFERÊNCIAS}

ARANHA, M. L. A. História da Educação e da Pedagogia, Geral e Brasil, 2006.

BUFFA, E. PINTO, G. A. Arquitetura e Educação: Organização do Espaço e Propostas Pedagógicas, 2002.

COOPERATIVO. Colégio Cooperativo. 20??. Disponível em: <http://www.colegiocooperativo.com.br/cooperativa.php?url=historia>. Acesso em: 05 abr. 2016.

FDE. Fundação para o Desenvolvimento da Educação. 2015. Disponível em: <http://www.fde.sp.gov.br/pagespublic/InternaFornecedores.aspx?contextmenu=sobrecattec>. Acesso em: 15 abr. 2016. 
FDE. Fundação para o Desenvolvimento da Educação. 2016. Disponível em: <http://catalogotecnico.fde.sp.gov.br/meu_site/index.html>. Acesso em: 15 abr. 2016.

KOWALTOWSKI, D. Arquitetura Escolar: o projeto do ambiente de ensino. 1. ed. São Paulo: Oficina de Textos, 2011.

MARIANO, J. L. M. Primeiro grupo escolar de Presidente Prudente : o contributo das professoras primárias (1925-1938). 1 ed. Curitiba: CRV, 2013.

MELATTI, S. P. D. P. C. A arquitetura escolar e a prática pedagógica. 2004. 120 f. Dissertação (Mestrado em Educação e Cultura) - Universidade do Estado de Santa Catarina (Centro de Ciências Tecnológicas), Joinville - $\quad$ SC. Disponível em: <http://www.tede.udesc.br/tde_busca/arquivo.php?codArquivo=277>. Acesso em: 12 jan. 2016.

NISKIER, A. Educação Brasileira: 500 anos de história. 1 ed. Rio de Janeiro: Funarte, 2001.

TEIXEIRA, E. As três metodologias. 2ae ed. São Paulo: Vozes, 2000. 